\title{
The fuel moisture content of peat in relation to meteorological factors
}

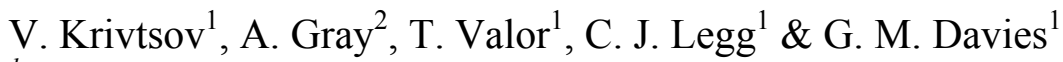 \\ ${ }^{l}$ CECS, The University of Edinburgh, UK \\ ${ }^{2}$ Centre for Ecology and Hydrology, UK
}

\begin{abstract}
This paper gives a brief overview of the important factors relating to fuel properties and the propagation of fire in peatlands, and presents a case study combining monitoring and modelling of factors related to peat fuel moisture in relation to meteorological changes. The discussion relates to the direct and indirect environmental effects of peat fires, and the significance of the results presented here in this regard. We also discuss the validity of Met Office Fire Severity Index (MOFSI), which is an almost direct implementation of the Canadian Wildland Fire Information System (CWFIS), and the relevance of the results obtained to the development of the weather prediction system designed specifically for the British conditions.
\end{abstract}

Keywords: peat, fuel, wild fire, meteorological variables, Penman equation.

\section{Introduction}

Large-scale wildfire outbreaks are sporadic in the UK $[1,2]$ but when they occur they can have serious environmental impacts [3]. Underground fires in peatlands are relatively rare events but when active they can smoulder for long periods of time causing significant environmental damage [4], and emit large quantities of combustion products, including greenhouse gases, into the atmosphere[5]. In other areas, particularly in the tropics, this can cause a deterioration in air quality and public health concerns [6]. Peat fires spread slowly at rates of approximately $3 \mathrm{~cm} / \mathrm{hr}$ [7]. They are fed by small but continuous quantities of air diffusing through the peat and flowing through fractured strata, cracks and groundwater pipe networks $[8,9]$. Laboratory work has shown that peat smouldering behaviour is influenced by moisture and mineral content [10]. A combination of 
ecological and hydrological assessment of peatlands is therefore indispensable for understanding fire hazard and risk and the sustainable management of peatland ecosystems [11].

Belowground reduced heat losses and the high thermal inertia of the peat, together with continual fuel availability and reduced oxygen supply, promote long-term smouldering combustion and allow for creeping but extensive propagation both in depth and in area. These fires are difficult to detect and frustrate most efforts to extinguish them. Smouldering fires may be caused by, for example, transition from a flaming wildfire or management fire or from an incompletely extinguished camp fire. Below we present the results of a case study carried out in a Scottish peatland to establish the relationships between the variability of moisture content and the concurrent changes of meteorological variables.

\section{Methodology and results}

A weather station was set up in the Pentland Hills (near Edinburgh, approximate position $55^{\circ} 51^{\prime} \mathrm{N}, 3^{\circ} 18^{\prime} \mathrm{W}$ ) to monitor changes in peat fuel moisture content in relation to changes in net solar radiation, wind speed and direction, air temperature and relative humidity, surface wetness, rainfall, and soil temperature and resistance. The data collected to date cover a three-week period of drought in late August - early September 2007, that ended on 16 September (day 259 - see Fig.1) with an intense rainstorm event. Over the course of the observed period values of soil resistance gradually increased, before dropping sharply after the intensive rainfall. Realised soil moisture deficit (SMD) was modelled using data on rainfall and potential evapotransiration (calculated using Penman's method [12]). Changes in the modelled SMD (Fig.2) appear to correspond to the observed changes in the soil water potential.

In order to relate changes in weather conditions to peat fuel moisture content (water content of samples on a percent of dry weight basis) soil cores were in five $2 \mathrm{~m} \times 2 \mathrm{~m}$ plots located close to the weather station. One core was taken from a random point in each plot on each of four sampling dates. Samples collected during the drought period (taken on Sep 7, i.e. day 250) had a mean moisture content of $75.2 \%$ and appeared to be significantly different (ANOVA, 95\% probability level) from the those collected during wet periods (e.g. on Oct 10: mean FMC $=78.0 \%$ ). The data were characterised by high variability with large standard deviations of mean values (Fig. 3). This variability was particularly noticeable at greater depths, and was primarily cause by relatively high moisture content registered at plot 4 , presumably due to the close proximity of the mineral horizon, which might have acted as a water source. The effect of depth was not, however, statistically significant though after removing the outliers (2 deep samples from Plot 4$)$, the effect of depth became significant at the $90 \%$ probability level.

The Duff Moisture Code (DMC) of the Canadian Wildland Fire Information System (CWFIS, [13]) is designed to reflect changes in the moisture content of loosely compacted duff and organic soils in the boreal forest. A preliminary 

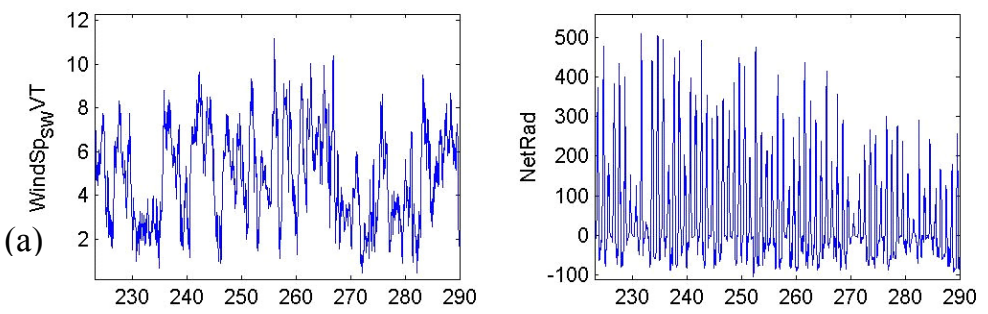

(b)
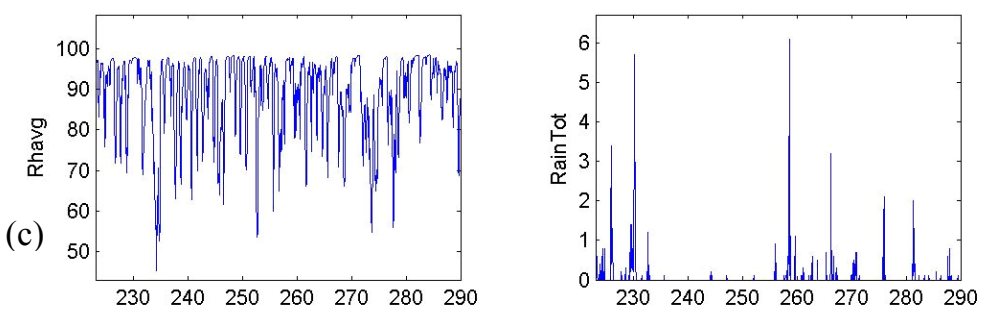

(d)
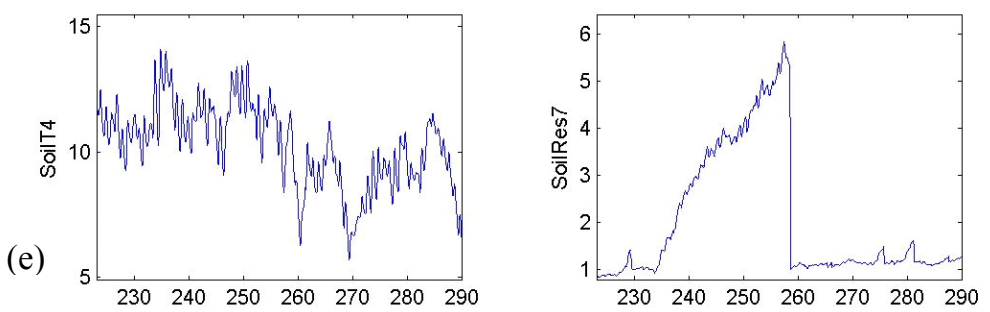

(f)
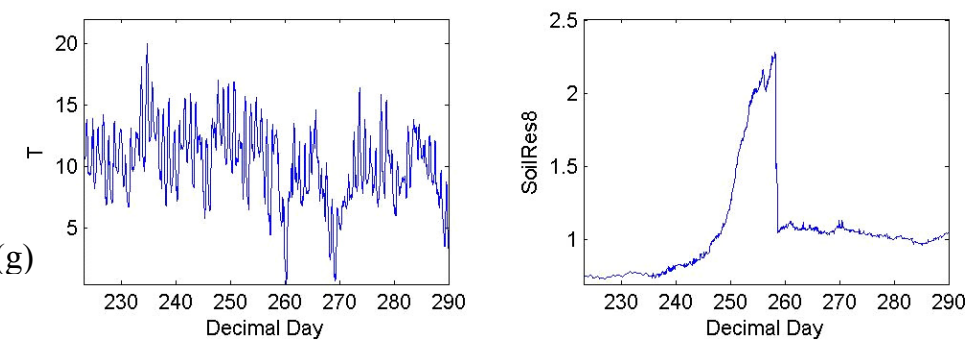

(h)

Figure 1: Selected monitoring data (a) wind speed; (b) net radiation; (c) relative humidity; (d) rainfall; (e) soil temperature $20 \mathrm{~mm}$ below surface; (f) soil resistance $100 \mathrm{~mm}$ below the surface; (g) screen temperature; (h) soil resistance $20 \mathrm{~mm}$ below the surface. 
(a)

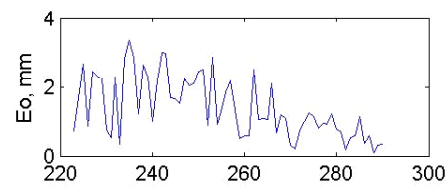

(c)

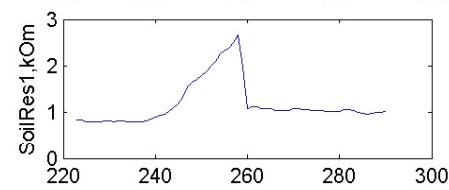

(e)

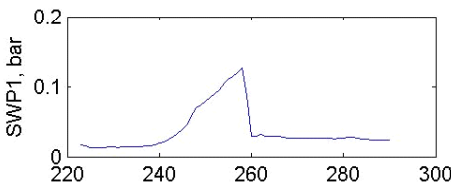

(g)

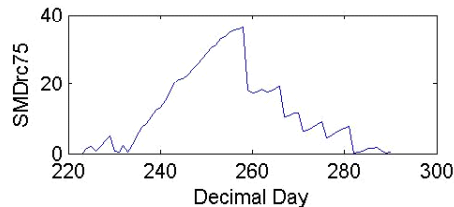

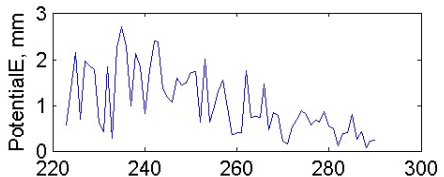

(b)

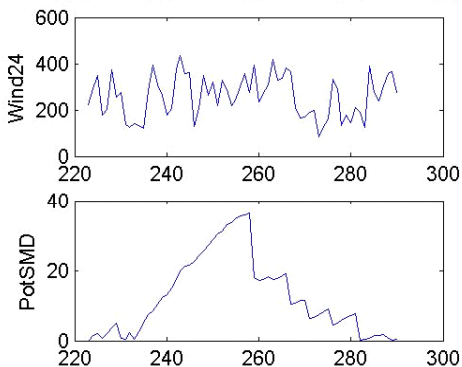

(d)

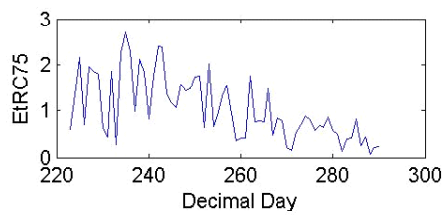

Figure 2: Calculated values of potential evaporation, evapotranspiration, and potential and realised SMD $(\mathrm{mm})$ are plotted together with the monitoring data on soil resistance and water potential. (a) evaporation form open water surface; (b) potential evapotranspiration; (c) soil resistance; (d) wind speed (miles per day); (e) measured soil water potential; (f) potential soil moisture deficit; (g) realised soil moisture deficit; (h) realised evapotranspiration. Note that realised and potential soil moisture and evapotranspiration are similar due to the low levels of water stress.

visual examination of DMC values suggests that it corresponds relatively well to modelled changes in SMD, as well as to changes in the recorded values of soil resistance and calculated values of SWP.

Laboratory studies are currently underway to provide relationships between soil resistance and the peat fuel moisture content, and to estimate the likelihood of ignition at different moisture contents [14]. In the future, we intend to incorporate these relationships into a model that could be used as a predictive tool for assessing the probability of peat fire.

\section{Discussion}

The UK holds some substantial areas of blanket peat, and these areas are recognised as being of considerable global conservation interest [15]. Fire is 

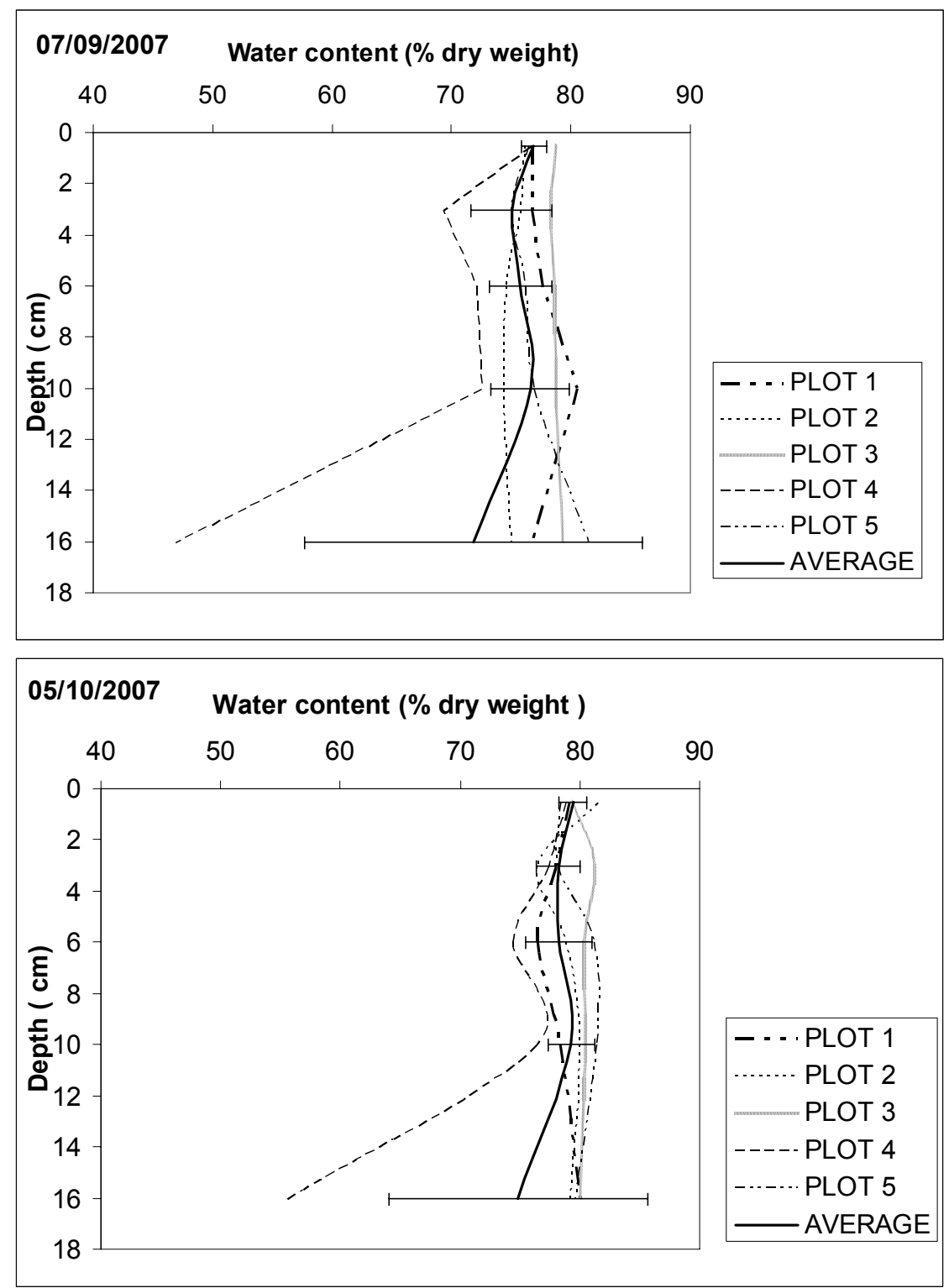

Figure 3: Depth profiles of the moisture content taken during a drought (7 Sep) and wet period (5 Oct). The difference in moisture content between these dates is significant (ANOVA) on the $95 \%$ probability level. 
widely used as a management tool in these areas and wildfires are not uncommon. When peat fires occur they cause significant ecological damage leaving some areas bare for decades if not centuries [3] and can release significant quantities of carbon. The results presented here are therefore important in both the local and the global context. Indeed globally the future of the peatlands is increasingly jeopardised by ongoing climate change. In the UK, climate change scenarios [16] suggest increases in mean temperature and evapotranspiration that are likely to result in lowered water tables and a consequent increase hazard of peat fires, particularly in summer. Furthermore, laboratory experiments have shown that elevated temperatures promote decomposition of peat samples exposed to drying cycles but have little effect on decomposition of continuously flooded samples [17], with subsequent effects on the emissions of greenhouse gasses such as methane and carbon dioxide [18]. The influence on the $\mathrm{N}_{2} \mathrm{O}$ emissions has also been studied [19].

It should also be noted that under certain conditions peat areas may exhibit a so-called sponge effect. For example, efficient removal of oxidised sulphate by wet deposition leads to its accumulation in the Indonesian peat areas, which serve as natural sponges, soaking up rain during the wet season and slowly

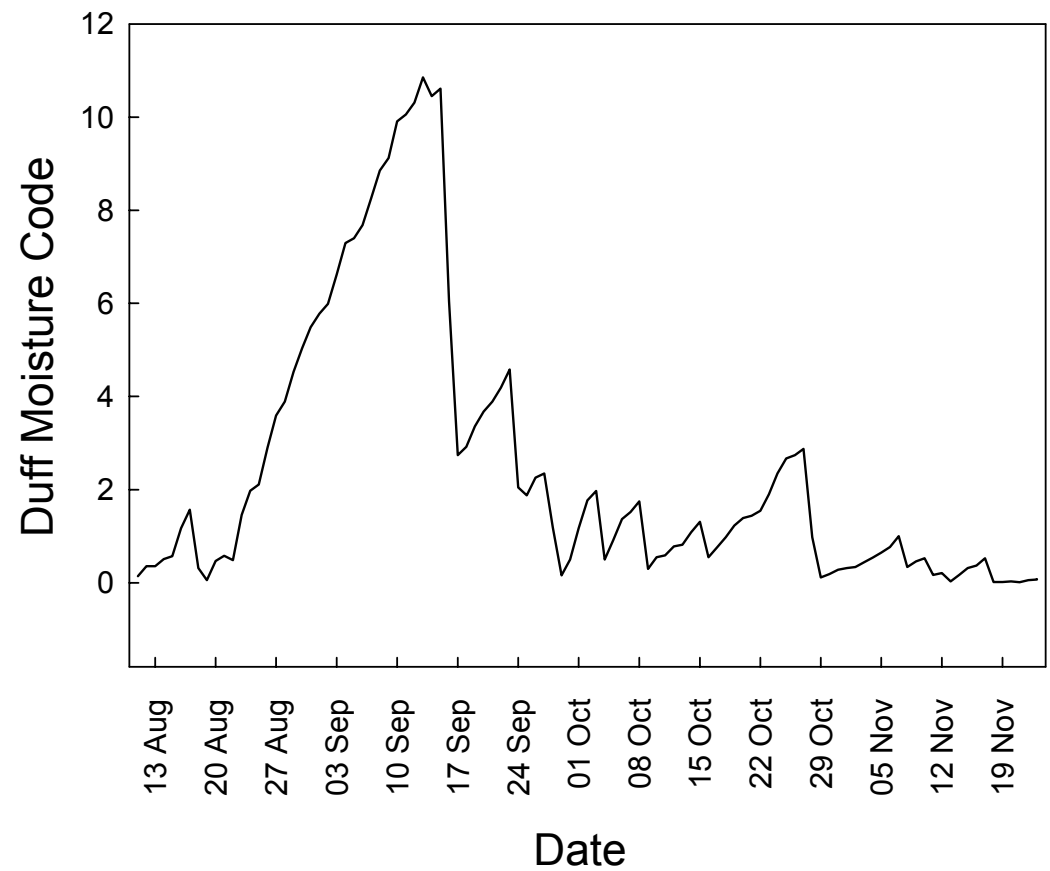

Figure 4: Modelled DMC changes throughout the study period. Note a gradual increase starting in late August and ending on 16 September (Julian Day 259). 
releasing moisture into the atmosphere during the dry season [20]. After the peat forests are drained (e.g. for land clearing purposes), the peat soil becomes drier and therefore extremely flammable. Consequently, the chemical composition and microphysical properties of emitted fire aerosol is influenced (among other factors) by the accumulated pollutants. As the probability of ignition and the characteristics of smouldering are dependent on moisture content, the results presented here are therefore also relevant to issues of pollution control.

The UK is in the process of developing a fire danger rating system and, the current (i.e. used by the Met Office) prediction system, the Met Office Fire Severity Index (MOFSI) is an almost direct implementation of the CWFIS [1] Existing research has highlighted the problems associated with applying the CWFIS to vegetation types which it was never designed to represent $[21,22]$ and this includes Calluna vulgaris-dominated peatlands in the UK The early data presented here suggests however that changes in the DMC (Fig. 4) may correspond fairly well to changes both in the measured soil resistance and in the modelled SMD. The current MOFSI system is designed for a very specific purpose: to detect "exceptional fire weather conditions" that may result in unacceptably high levels of ecological damage should a fire occur (Kitchen et al. 2006). If the system does indeed reflect changes in the moisture content, and therefore flammability, it will successfully capture one of the main controls governing when truly severe fires occur. Considering the above, the results presented here provide specific information which may be helpful in informing future improvements to MOFSI and the development of the weather prediction system designed specifically for the British conditions.

\section{References}

[1] Kitchen, K., et al., Developing a fire danger rating system for the United Kingdom. Forest Ecology and Management, 2006. 234S.

[2] Legg, C.J., et al., A Fire Danger Rating System for vegetation fires in the UK: The FireBeaters project phase I final report. 2007, The University of Edinburgh.

[3] Maltby, E., C.J. Legg, and M.C.F. Proctor, The Ecology of Severe Moorland Fire on the North York Moors - Effects of the 1976 Fires, and Subsequent Surface and Vegetation Development. Journal of Ecology, 1990. 78(2): p. 490-518.

[4] Rein, G., et al., The severity of smouldering peat fires and damage to the forest soil. Catena, 2008. in Press.

[5] Rein, G., S. Cohen, and A. Simeoni, Carbon Emissions from Smouldering Peat in Shallow and Strong Fronts. Proceedings of the combustion institute, 2008. 32: p. in Press.

[6] Wang, Y.H., R.D. Field, and O. Roswintiarti, Trends in atmospheric haze induced by peat fires in Sumatra Island, Indonesia and El Nino phenomenon from 1973 to 2003. Geophysical Research Letters, 2004. 31(4): p. -.

[7] Frandsen, W.H., Burning Rate of Smoldering Peat. Northwest Science, 1991. 65(4): p. 166-172. 
[8] Rein, G., S. Cohen, and S. A., Carbon emissions from smouldering peat in shallow and strong fronts. Proceedings of the Combustion Institute, 2008. 38.

[9] Holden, J. and T.P. Burt, Piping and pipeflow in a deep peat catchment. Catena, 2002. 48(3): p. 163-199.

[10] Reardon, J., R. Hungerford, and K. Ryan, Factors affecting sustained smouldering in organic soils from pocosin and pond pine woodland wetlands. International Journal of Wildland Fire, 2007. 16(1): p. 107-118.

[11] Zaidel'man, F.R. and S.V. Romanov, Ecological-hydrothermal assessment of pyrogenic soils of cutover peatlands. Eurasian Soil Science, 2007. 40(1): p. 82-92.

[12] Shaw, E.M., Hydrology in practice. 1983, Wokingham: Van Nostrand Reinhold (UK) Co. ltd. 569.

[13] Van Wagner, C.E., Development and Structure of the Canadian Forest Fire Weather Index System. 1987, Canadian Forestry Service: Ottawa.

[14] Rein, G., et al., The severity of smouldering peat fires and damage to forest soil. Catena, 2008. in press.

[15] Thompson, D.B.A., et al., Upland Heather Moorland in Great-Britain - a Review of International Importance, Vegetation Change and Some Objectives for Nature Conservation. Biological Conservation, 1995. 71(2): p. 163-178.

[16] Hulme, M., et al., Climate Change Scenarios for the United Kingdom: The UKCIP02 Scientific Report. 2002, Tyndall Centre for Climate Change Research, School of Environmental Sciences, University of East Anglia: Norwich, UK.

[17] Hogg, E.H., V.J. Lieffers, and R.W. Wein, Potential Carbon Losses from Peat Profiles - Effects of Temperature, Drought Cycles, and Fire. Ecological Applications, 1992. 2(3): p. 298-306.

[18] Nakano, T., et al., Temporal variations in soil-atmosphere methane exchange after fire in a peat swamp forest in West Siberia. Soil Science and Plant Nutrition, 2006. 52(1): p. 77-88.

[19] Takakai, F., et al., Effects of agricultural land-use change and forest fire on $\mathrm{N} 2 \mathrm{O}$ emission from tropical peatlands, Central Kalimantan, Indonesia. Soil Science and Plant Nutrition, 2006. 52(5): p. 662-674.

[20] Langmann, B. and H. Graf, Indonesian smoke aerosols from peat fires and the contribution from volcanic sulfur emissions. Geophysical Research Letters, 2003. 30(11): p. -.

[21] Davies, G.M., et al., Developing shrub fire behaviour models in an oceanic climate: Burning in the British uplands. Forest Ecology and Management, 2006. 234S.

[22] Anderson, S.A.J. Future option for fire behaviour modelling and fire danger rating in New Zealand. in Proceeding of the Bushfire Conference 2006: Life in a fire-prone environment: Translating science into practice. 2006. Brisbane. 